\title{
THE ACTION OF ESERINE SULPHATE ON THE SPINAL CORD OF THE CAT
}

\author{
BY \\ D. TAVERNER \\ From the Department of Medicine, University of Leeds
}

(RECEIVED OCTOBER 13, 1953)

Feldberg (1951), reviewing the pharmacology of central synaptic transmission, classified the evidence in favour of the hypothesis that acetylcholine acts as a central transmitter under three headings: 1 , direct effects of acetylcholine on the central nervous system; 2 , the acetylcholine content of nervous tissue; 3 , the action of anticholinesterases on the activity of the central nervous system.

Much of the evidence for the last has been obtained from the study of the action of eserine on spinal reflex activity in mammals, using the classical methods of reflex elicitation and recording. A review of this evidence shows general agreement that eserine has a stimulant action on spinal reflex activity; but there are differences concerning its action on individual reflexes, and on the influence of the previous administration of atropine. Some of this conflict is evidently due to differences in the preparations used and the mode of administration of the drug, but it has also been noted that the action of eserine is irregular and unpredictable (Calma and Wright, 1944).

Schweitzer and Wright (1937) found that the intravenous injection of eserine in doses of 0.03$0.2 \mathrm{mg} . / \mathrm{kg}$. into cats anaesthetized with chloralose markedly increased the knee jerk and general reflex excitability. Calma and Wright (1947) reported similar changes in the knee jerk after the intrathecal administration of eserine, but found variable changes in the flexor reflex. Merlis and Lawson (1939) stated that both intravenous and intrathecal administration of eserine depressed the knee jerk and augmented the flexor reflex; similar results were reported by Bülbring and Burn (1941) using intra-aortic injection in the dog.

This paper reports investigations into the action of eserine on the spinal cord of the cat, using methods developed in previous studies of the action of drugs on the central nervous system (Bernhard and Taverner, 1951; Bernhard, Taverner, and Widén, 1951; Taverner, 1952, 1953). Mono- synaptic and polysynaptic reflex discharges and cord dorsum potentials were evoked by electrical stimulation of appropriate afferent fibres in motor and sensory nerves in unanaesthetized preparations. The only previous report on the action of eserine, using comparable methods, is that of Wikler (1945), who found that the intravenous injection of eserine into spinal cat preparations increased the amplitude of monosynaptic flexor and extensor reflex responses and had no effect on polysynaptic flexor reflex responses.

\section{Materials AND Methods}

Cats were used in all experiments. Decerebration or spinal section was carried out under ether anaesthesia, but the effects of the latter had disappeared when the experiments were performed two or three hours later. All dissection and manipulation of nervous structures were performed under warm paraffin oil. The standard electro-physiological technique employed has been described (Bernhard and Taverner, 1951; Taverner, 1952). The rate of stimulation was once every four seconds. All the drugs employed were injected slowly through an indwelling polythene tube which was passed up the superior mesenteric artery so that its tip lay in the aorta above the origins of the lumbar vessels. The drugs used in various experiments were freshly prepared eserine sulphate $(0.1 \%)$, strychnine hydrochloride $(0.01 \%)$ and pentobarbitone sodium (Nembutal) $(0.5 \%)$.

\section{RESULTS}

Electrical stimulation of low threshold afferent fibres (Group 1) in the gastrocnemius nerve is followed, after an interval of $2.5-3.0$ msec., by a synchronous reflex discharge in the $S 1$ ventral root (Fig. 1A). It has been shown by Lorente de Nó (1935), Renshaw (1940), and Lloyd (1943) that this discharge represents activity in two neuronal (monosynaptic) reflex arcs and returns to the muscle from which the afferent fibres arise. Myotatic reflexes-tendon jerks-are probably of this type. If the stimulus is applied to a cutaneous 


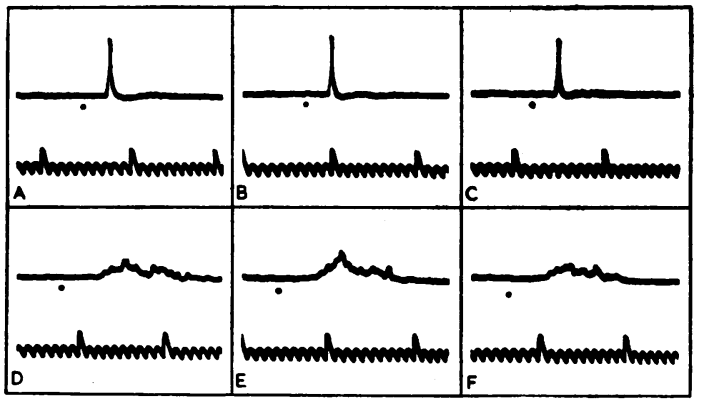

FiG. 1.-Effect of eserine on the monosynaptic extensor (upper series) and polysynaptic flexor (lower series) reflex responses. A, D, controls. B, E, 1 min., C, F, 20 min., after intra-aortic injection of $0.1 \mathrm{mg}$. eserine sulphate per kg. Dots indicate moment of stimulation. Time in msec.

nerve, such as the sural, an asynchronous, irregular discharge appears in the S1 ventral root after 4-5 msec. and persists for $10 \mathrm{msec}$. or more (Fig. 1D). Lloyd (1943) has shown that this discharge represents activity in more complex reflex arcs with several interpolated internuncial neurones (polysynaptic reflexes); flexor and crossed extension reflexes are believed to depend on such polysynaptic chains.

\section{Effect of Intravenous Eserine on Spinal Reflexes in Unanaesthetized Preparations}

In a series of preliminary experiments eserine sulphate, $0.1-0.2 \mathrm{mg} . / \mathrm{kg}$. body weight, was administered by slow intravenous injection to decerebrate and to high and low spinal preparations. The polysynaptic reflex response increased in amplitude to $130-150 \%$ of the pre-injection value in all types of preparation. The latency of the effect varied from 30 to more than 150 seconds. In decerebrate preparations there was an increase in the amplitude of the monosynaptic extensor reflex response in all the experiments save one. In preparations with spinal cord section at various levels the results were irregular and unpredictable, but the monosynaptic extensor reflex response was rarely augmented by eserine; it was mostly either unaffected or reduced in amplitude. Analysis of these results suggested that the variability was due to the hypotensive effect of intravenous eserine. In the decerebrate preparations this was of little significance because of the relatively high initial blood pressure values. In preparations with spinal section the initial blood pressure was usually between $50-60 \mathrm{~mm}$. $\mathrm{Hg}$, and a fall to $40 \mathrm{~mm}$. $\mathrm{Hg}$ or less was frequently observed. It is known that a blood pressure level of $40 \mathrm{~mm}$. $\mathrm{Hg}$ is critical for the functioning of the spinal reflexes (Taverner, 1953).
Effect of Intra-aortic Eserine on the Spinal Reflexes in Unanaesthetized Preparations

Consistent results were obtained in a series of experiments where the eserine was injected slowly through a polythene tube inserted into the aorta via the superior mesenteric artery so that its tip lay above the site of origin of the lumbar arteries. This tube was filled with normal saline between injections and was controlled with a three-way tap from a Greenfield lumbar puncture needle.

Fig. 1 shows the effect of $0.1 \mathrm{mg}$. $/ \mathrm{kg}$. eserine injected into the aorta of a decerebrate cat with the spinal cord sectioned in the upper cervical region. The reflexes were sampled alternately at $2 \mathrm{sec}$. intervals. Fig. 1A shows the monosynaptic extensor reflex response evoked by electrical stimulation of the gastrocnemius nerve, and Fig. 1D the polysynaptic reflex response elicited from the sural nerve, before the administration of eserine. Figs. $1 B$ and 1C show that the monosynaptic reflex response is unchanged $1 \mathrm{~min}$. and $20 \mathrm{~min}$., respectively, after the eserine. The polysynaptic reflex response is increased $1 \mathrm{~min}$. later (Fig. 1E), but has returned to its pre-injection level $20 \mathrm{~min}$. later (Fig. 1F). Doses of eserine of less than $0.1 \mathrm{mg} . / \mathrm{kg}$. body weight had no significant effect on either reflex under these experimental conditions.

Larger doses of eserine produced more striking results. Figs. $2 \mathrm{~A}$ and $\mathrm{D}$ show the monosynaptic extensor and polysynaptic reflex responses, respectively, before the administration of $0.2 \mathrm{mg} . / \mathrm{kg}$. body weight of eserine by intra-aortic injection in a decerebrate preparation with high spinal section. Figs. $2 B$ and $E$ show the two reflexes $1.5 \mathrm{~min}$. after the injection, and Figs. $2 \mathrm{C}$ and $\mathrm{F} 30 \mathrm{~min}$. after the injection. Both reflexes nearly doubled in size shortly after the injection.

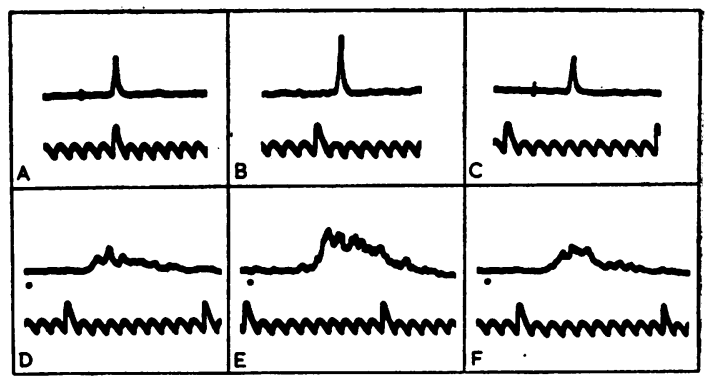

FIG. 2.-Effect of eserine on the monosynaptic extensor (upper series) and polysynaptic flexor (lower series) reflex responses. A, D, controls. B, E, 1.5 min., C, F, 30 min., after intra-aortic injection of $0.2 \mathrm{mg}$. eserine per $\mathrm{kg}$. Time in msec. 


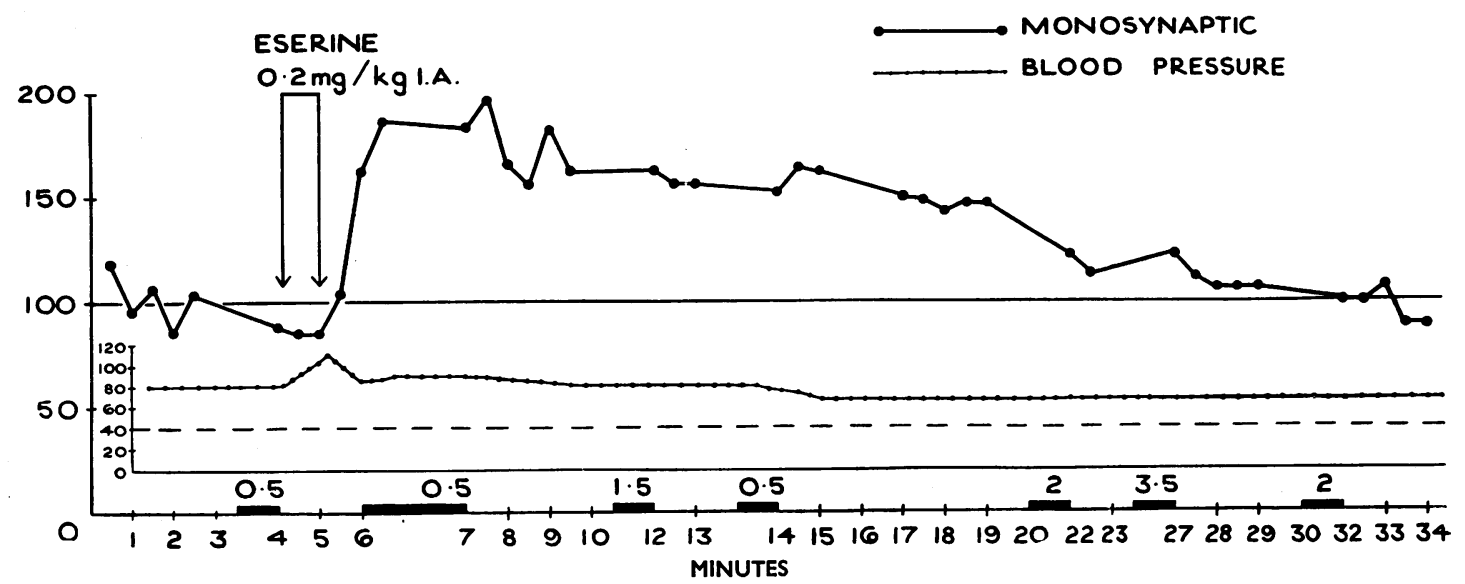

FIG. 3.-Effect of $0.2 \mathrm{mg}$. $/ \mathrm{kg}$. eserine sulphate on the monosynaptic extensor reflex response and blood pressure. (Same experiment as Fig. 2.) Ordinates: Reflex response as percentage of pre-injection amplitude (main graph). Blood pressure in mm. of mercury (lower inset graph), Abscissae: Time in min. Bars on base line represent suspension of recording.

The time course of these changes is demunstrated in Figs. 3 and 4 . In Fig. 3 the amplitude of the monosynaptic extensor reflex response is expressed as a percentage of the mean pre-injection level. Sampling of the reflex continued throughout the injection of eserine. Thirty seconds after the end of the injection the amplitude of the monosynaptic reflex response increased rapidly to $185 \%$ of the pre-injection level. The increase persisted for $2 \mathrm{~min}$. and then, after a fairly rapid fall in amplitude, a level of $160 \%$ was maintained for a further $10 \mathrm{~min}$. The monosynaptic reflex then declined slowly in amplitude and returned to the pre-injection value $30 \mathrm{~min}$. after the injection. The blood pressure was recorded throughout and rose during the injection from a previously steady level of $80 \mathrm{~mm}$.
$\mathrm{Hg}$ to $110 \mathrm{~mm}$. Hg. During the next minute it fell again to $90 \mathrm{~mm}$. $\mathrm{Hg}$ and $4 \mathrm{~min}$. later had reached the original level of $80 \mathrm{~mm}$. $\mathrm{Hg}$. Nine minutes after the injection the blood pressure fell to $70 \mathrm{~mm}$. $\mathrm{Hg}$ and remained at this level until the end of the experiment.

Fig. 4 shows the changes in the polysynaptic reflex response in the same experiment. The results are expressed in the same way as in Fig. 3. The augmentation of the polysynaptic reflex response after the intra-aortic injection of $0.2 \mathrm{mg} . / \mathrm{kg}$. eserine is almost identical with that of the monosynaptic reflex response. The initial increase to $190 \%$ of the pre-injection level began $30 \mathrm{sec}$. after the end of the injection.

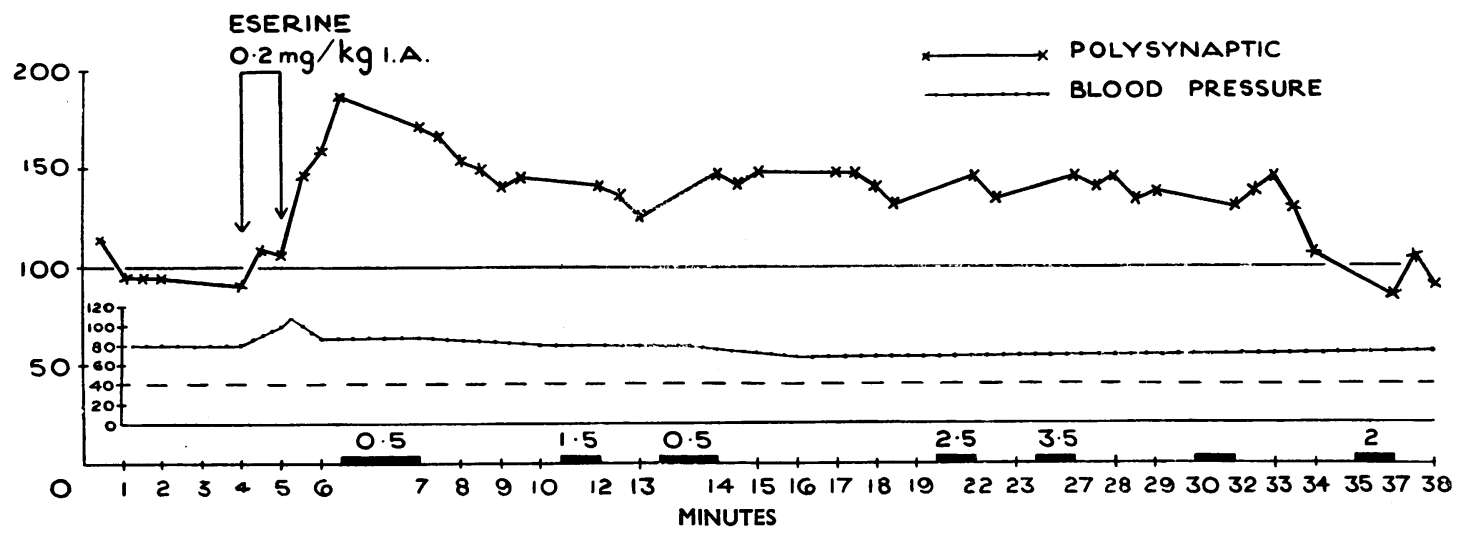

Fio. 4.-Effect of eserine on the polysynaptic flexor reflex response. (Same experiment as Figs. 2 and 3.) Ordinates and abscissae as in Fig. 3. 


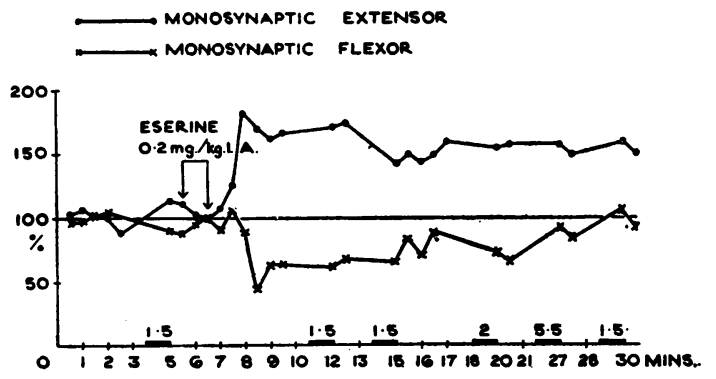

Fig. 5.-Effect of $0.2 \mathrm{mg} . / \mathrm{kg}$. eserine on the monosynaptic extensor (filled circles) and monosynaptic flexor reflex responses. Ordinate: reflex response as percentage of pre-injection amplitude. Abscissa: time in $\mathrm{min}$.

Similar increases in both the monosynaptic extensor and polysynaptic reflex responses occurred in all experiments with decerebrate and with high or low spinal preparations when the eserine was given by intra-aortic injection. The arterial blood pressure always rose during the intra-aortic injection of eserine, in contrast to the fall in blood pressure produced by intravenous injection.

\section{Effect of Intra-aortic Eserine on the Monosynaptic Flexor Reflex in Unanaesthetized Preparations}

Monosynaptic reflex responses can also be elicited by electrical stimulation of low threshold fibres in the nerves supplying flexor muscles of the limbs. Such monosynaptic flexor reflexes may be affected by drugs in a different manner from monosynaptic extensor reflexes (cf. Bernhard and Taverner, 1951).

Fig. 5 shows the effects of the intra-aortic injection of eserine on the monosynaptic extensor reflex evoked by stimulation of muscle afferent fibres in the nerve to one head of the gastrocnemius muscle and on the monosynaptic flexor reflex elicited from the nerve to the hamstring muscles in a decerebrate preparation with high spinal section. The injection of $0.2 \mathrm{mg} . / \mathrm{kg}$. eserine increases the amplitude of the monosynaptic extensor reflex response in the manner already described (Figs. 2 and 3). Coincident with the rise in the extensor response there is a rapid fall in the amplitude of the monosynaptic flexor response to less than $50 \%$ of its pre-injection value. This reduction is maintained for some minutes and the flexor reflex then slowly regains its normal size, which it reaches after about $25 \mathrm{~min}$., when the extensor response is still $150 \%$ of the pre-injection level.

\section{Effect of Intra-aortic Eserine in De-afferented Preparations}

The injection of an anticholinesterase such as eserine leads to widespread muscular twitching.
It is possible that afferent impulses during this period might lead to changes in the excitability of the spinal cord and thus account for the alterations in the reflex responses described above.

Control experiments were therefore performed in which the spinal cord was cut at the junction of the T12-L1 segments and all the dorsal roots on both sides from L2 downwards were sectioned intradurally. In addition the L7 and S1 ventral roots were severed intradurally. Electrical stimulation of the $\mathrm{S} 1$ dorsal root produces a complex reflex discharge in the S1 ventral root composed of monosynaptic and polysynaptic elements. The intra-aortic injection of eserine into such preparations increased the amplitude of the polysynaptic reflex response to approximately twice the preinjection level. The monosynaptic reflex response was depressed to a varying degree, but both reflexes had returned to their pre-injection values $20 \mathrm{~min}$. later. The monosynaptic reflex response probably falls because afferents of the monosynaptic flexor reflex are also travelling in the S1 dorsal root (cf. Fig. 5). This response of the spinal cord isolated from afferent impulses suggests that the action of eserine is central.

\section{Effect of Intra-aortic Eserine on the Cord Dorsum Potentials}

It has been known for many years that electrical stimulation of cutaneous afferent fibres produces potential changes in the spinal cord (Gotch and Horsley, 1891; Gasser and Graham, 1933; Barron and Matthews, 1938; Lloyd and McIntyre, 1944; and Eccles, 1946). When the sural nerve is stimulated records obtained from a monopolar electrode resting on the dorsal surface of the S1 segment of the spinal cord consist of an initial negative wave followed by a varying degree of positivity. Bernhard (1953) has suggested that the first wave of negativity represents activity in monosynaptically

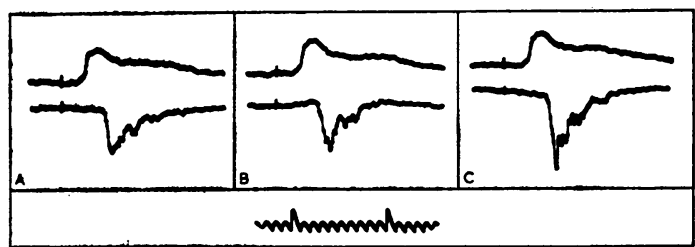

FIG. 6.-Effect of eserine on the cord dorsum potentials (upper series) and polysynaptic flexor reflex response (lower series) elicited by electrical stimulation of the sural nerve. A, control. B, $1 \mathrm{~min}$., C, $18 \mathrm{~min}$., after $0.18 \mathrm{mg}$. eserine sulphate per $\mathrm{kg}$. by intra-aortic injection. Polysynaptic response recorded negativity downwards. Time in msec. 
activated cell bodies in the dorsal grey matter concerned in the upward transmission of afferent impulses. The inconstant positivity, which can be greatly accentuated by the intravenous injection of strychnine, originates from propriospinal interneurones extending over several segments of the spinal cord, which are not essential for reflex transmission.

Fig. 6A shows the cord dorsum potentials (upper beam) evoked by electrical stimulation of the sural nerve in a decerebrate preparation with high spinal section. The lower beam shows the polysynaptic reflex response simultaneously recorded from the S1 ventral root. Fig. 6B records the two responses $1 \mathrm{~min}$. after the intra-aortic injection of $0.18 \mathrm{mg}$. $/ \mathrm{kg}$. eserine. The cord dorsum potentials are unchanged, but the polysynaptic reflex response is beginning to increase in size. $18 \mathrm{~min}$. after the injection (Fig. 6C) the cord dorsum potentials are unchanged, but the polysynaptic reflex response is now considerably augmented. In further experiments it was found that eserine did not modify the cord dorsum potentials even after the positive component had been greatly increased by the administration of strychnine.

\section{Influence of the Administration of Pentobarbitone and Atropine on the Action of Eserine}

Fig. 7A shows the control monosynaptic extensor reflex response evoked by electrical stimulation of the nerve to the gastrocnemius muscle in a decerebrate preparation. Fig. 7B records the reduction in size of the reflex $45 \mathrm{~min}$. after the intravenous

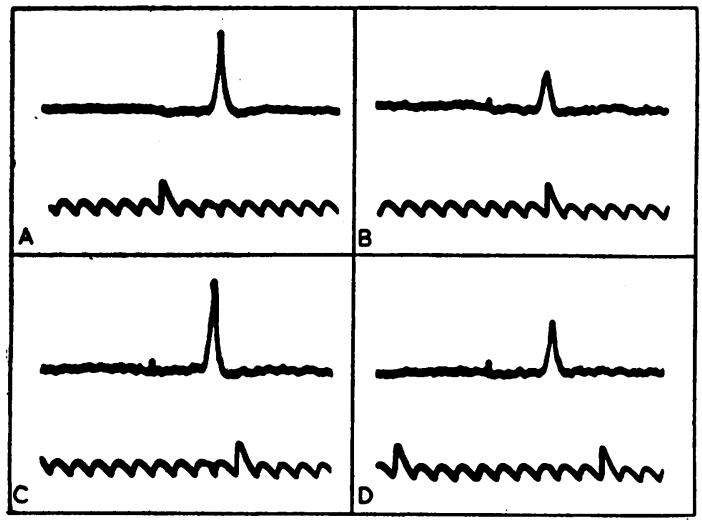

FIG. 7.-Effect of eserine on the monosynaptic extensor reflex response depressed by pentobarbitone sodium. A, control. B, $45 \mathrm{~min}$. after $5.5 \mathrm{mg}$. pentobarbitone per $\mathrm{kg}$. by intra-aortic injection. C, $3 \mathrm{~min}$. after $0.2 \mathrm{mg}$. eserine sulphate per $\mathbf{~ k g}$. by intra-aortic injection. $\mathrm{D}, 15 \mathrm{~min}$. after eserine. Time in $\mathrm{msec}$. injection of $5.5 \mathrm{mg} . / \mathrm{kg}$. of pentobarbitone sodium. Between records $7 \mathrm{~B}$ and $7 \mathrm{C}, 0.2 \mathrm{mg}$. $/ \mathrm{kg}$. eserine was injected intravenously and $3 \mathrm{~min}$. later (Fig. 7C) the reflex response had returned to its original size. This increase was short-lived, and $15 \mathrm{~min}$. after the eserine injection the monosynaptic reflex was again in its depressed state. The time course of these changes is shown in Fig. 8. The monosynaptic reflex response is plotted in terms of the pentobarbitone-depressed response as $100 \%$. The injection of $0.2 \mathrm{mg} . / \mathrm{kg}$. eserine doubles the size of the monosynaptic reflex response, but the effect is short-lived and has almost disappeared $13 \mathrm{~min}$. later.

In some experiments atropine sulphate was injected intravenously, or into the aorta, before the administration of eserine. $0.75 \mathrm{mg} . / \mathrm{kg}$. atropine sulphate injected into the aorta abolished the effect of a subsequent dose of $0.2 \mathrm{mg} . / \mathrm{kg}$. eserine

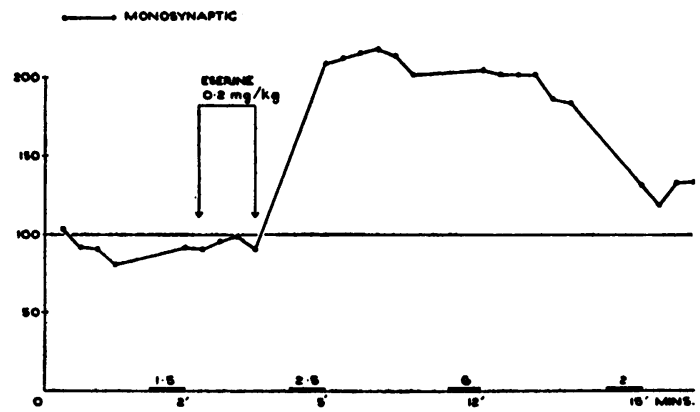

Fig. 8.-Effect of intra-aortic eserine on the monosynaptic reflex depressed by the administration of $5.5 \mathrm{mg}$. pentobarbitone per kg. $45 \mathrm{~min}$. previously. Ordinate: reflex response as percentage of pre-injection amplitude. Abscissa: time in min.

on the monosynaptic and polysynaptic reflex responses in a high-spinal preparation. Smaller doses of atropine diminished the central action of eserine.

\section{Discussion}

The initial experiments with intravenously administered eserine gave unpredictable results, confirming the findings of Calma and Wright (1944). The only exception was in decerebrate preparations in which both the monosynaptic extensor and polysynaptic reflex responses were regularly augmented by intravenous eserine. These results were probably due to the hypotensive action of intravenous eserine, which in the spinal preparations frequently lowers the blood pressure to $40 \mathrm{~mm}$. $\mathrm{Hg}$ - the critical value 
for satisfactory reflex responses. The consistent results obtained after the intra-aortic injection of eserine, which raised the blood pressure, enabled a more accurate analysis of the action of eserine on the central nervous system to be made. The method of approach through the superior mesenteric artery proved more satisfactory than the insertion through the femoral artery employed by Skoglund (1953) which occasionally interfered with the blood supply to the site of stimulation in the leg.

The results obtained confirm and amplify the findings of Schweitzer and Wright (1937). Eserine doubles the size of both the monosynaptic extensor and polysynaptic reflex responses in all types of preparation used, and this effect is not abolished by the previous administration of a barbiturate in doses which markedly depress the spinal reflexes. The differences between the present results and those of Merlis and Lawson (1939) and Bülbring and Burn (1941) are probably attributable to the different preparations and mode of administration of the drug which were employed. The results of Wikler (1945), who used comparable electrophysiological methods, agree with the present findings only in respect of the increase of the monosynaptic extensor reflex response after eserine administration. Wikler reported no effect on the polysynaptic flexor reflex response, and an increase in the monosynaptic flexor response, in contrast to the decrease in the amplitude of the latter reflex which was found in this investigation. The discrepancy can hardly be attributed to the different method of drug administration used.

Although the stimulant effect of eserine sulphate on spinal cord activity appears to be established, there remains the possibility that its action is a direct one and does not depend on its anticholinesterase properties. It is probably significant that other anticholinesterases, such as tabun (Skoglund, 1953) and diisopropyl fluorophosphonate (Chennels, Floyd, and Wright, 1951), have been shown to have a similar effect to eserine on the spinal cord. Further, Schweitzer, Stedman, and Wright (1939) showed that the conversion of eserine to eseroline, by the removal of the urethane grouping said to be responsible for the anticholinesterase activity, also eliminated the action of eserine on the spinal cord. Again the abolition of the central effects of eserine by the prior administration of atropine also favours the view that this central action is a manifestation of the anticholinesterase activity of eserine.
If this last view be accepted, then it is evident that not all central synaptic activity can be related to the presence of acetylcholine. Most forms of spinal reflex activity are augmented by eserine, but the cord dorsum potentials are unaffected. This is to be expected for the N1 potential-which derives from monosynaptically activated cells in the dorsal grey matter concerned in afferent transmission-because it is known that posterior roots contain no acetylcholine or choline acetylase (Feldberg, 1951). The primary sensory fibres are unlikely, therefore, to possess cholinergic endings. The $\mathbf{P}$ component of the cord dorsum potentials might be expected to respond to eserine, because the $P$ potential is believed to represent interneuronal activity, and Feldberg, Gray, and Perry (1953) have suggested that intra-arterially administered acetylcholine acts upon the interneurones. However, these authors used different methods and did not study the effect of acetylcholine on the cord dorsum potentials. The potential cannot be regarded as a quantitative indicator of interneuronal activity and very probably derives from only part of the spinal interneurones. The present results may imply that these neurones are not cholinergically activated; but Skoglund (1953) showed that the powerful anticholinesterase tabun abolished the $\mathrm{P}$ component, and this may have been due to the activation of excessive amounts of acetylcholine, giving a depressant effect. Investigation of the central effects of other anticholinesterases may help to explain these discrepancies.

\section{SUMMARY}

1. The action of eserine sulphate on the activity of the spinal cord in the cat has been investigated in unanaesthetized, decerebrate, and spinal preparations.

2. Intravenous administration was found to be unsatisfactory because of the effect on the blood pressure, but intra-aortic injection gave consistent results.

3. Intra-aortic eserine sulphate increases the amplitude of the monosynaptic extensor and polysynaptic flexor reflex responses and decreases the amplitude of the monosynaptic flexor reflex response. It has no effect on the cord dorsum potentials evoked by electrical stimulation of cutaneous afferent nerve fibres. 


\section{RFFERENCES}

Barron, D. H., and Matthews, B. H. C. (1938). J. Physiol., 92, 276.

Bernhard, C. G. (1953). In The Spinal Cord (Ciba Foundation Symposium), p. 43. London: Churchill.

- and Taverner, D. (1951). Brit. J. Pharmacol., 6, 540.

— and Widén, L. (1951). Ibid., 6, 551.

Bülbring, E., and Burn, J. H. (1941). J. Physiol., 100, 337.

Calma, I., and Wright, S. (1944). Ibid., 103, 93.

- (1947). Ibid., 106, 80.

Chennels, M., Floyd, W. F., and Wright, S. (1951). Ibid., 114, 107.

Eccles, J. C. (1946). J. Neurophysiol., 9, 87.

Feldberg, W. (1951). Arch. int. Physiol., 59, 544.

Gray, J. A. B., and Perry, W. L. M. (1953). J. Physiol., 119, 428.
Gasser, H. S., and Graham, H. T. (1933). Amer. J. Physiol., 103, 303.

Gotch, F., and Horsley, V. (1891). Philos. Trans. B., $182,267$.

Lloyd, D. P. C. (1943). J. Neurophysiol., 6, 293.

and McIntyre, A. K. (1944). J. gen. Physiol., 32, 409.

Lorente de Nó, R. (1935). Amer. J. Physiol., 112, 595.

Merlis, J. K., and Lawson, H. (1939). J. Neurophysiol., 2, 566.

Renshaw, B. (1940). Ibid., 3, 373.

Schweitzer, A., and Wright, S. (1937). J. Physiol., 89, 165. Stedman, E., and Wright, S. (1939). Ibid., 96, 302.

Skoglund, C. R. (1953). In The Spinal Cord (Ciba Foundation Symposium), p. 195. London: Churchill.

Taverner, D. (1952). Brit. J. Pharmacol., 7, 665. (1953). In The Spinal Cord (Ciba Foundation Symposium), p. 231. London: Churchill.

Wikler, A. (1945). Proc. Soc. exp. Biol. Med., 58, 193. 